\title{
Sensibilidade no diagnóstico da desnutrição protéico- calórica realizado pelas equipes de saúde por meio do SIAB e de busca ativa de casos.
}

\author{
The sensitivity of malnutrition diagnosis \\ using the SIAB and active search of cases.
}

Tatiana Monteiro Fiúza*

Marco Túlio Aguiar Mourão Ribeiro**

\begin{abstract}
Resumo
É atribuição da Atenção Primária á Saúde e da Estratégia de Saúde da Família (ESF) atuar na promoção e na manutenção do estado de saúde da população infantil por meio do atendimento e acompanhamento integrais. Para a atuação das equipes de saúde é fundamental a análise de saúde das populações cobertas. Para esse fim o Sistema de Informação da Atenção Básica (SIAB) é instrumento de valor inestimável. O objetivo deste estudo foi demonstrar a sensibilidade no diagnóstico da desnutrição protéico-calórica realizado pelas equipes de Saúde da Família, quando são utilizados apenas dados primários como instrumentos de busca da adequação e posterior informação destes, via SIAB, e por meio da busca ativa de crianças de 0 a 23 meses e 29 dias e obtenção de seus dados antropométricos delas. Tratase de estudo seccional, realizado no município de Patos de Minas (MG), de janeiro a abril de 2005. As prevalências de desnutrição protéico-calórica informadas no SIAB foram 2,35\% e 2,5\%, nas equipes A e B, respectivamente. As prevalências de desnutrição encontradas a partir da busca ativa, dos dados antropométricos e do cálculo dos índices peso-idade foram $14,12 \%$ e 13,75\% nas equipes A e B, respectivamente. Essas foram superiores à prevalência descrita pela Pesquisa Nacional de Demografia e Saúde, cuja prevalência foi 5,7\%. As prevalências de desnutrição protéico-calórica com base no índice peso-idade, mediante exclusivamente a utilização do SIAB como fonte de dados, levam ao subdiagnóstico do problema. Tratando-se o SIAB de um sistema de informação "territorializado", cujos dados possibilitam a construção de indicadores populacionais referentes a áreas de abrangência bem-delimitadas, propomos a avaliação crítica e constante desses dados.
\end{abstract}

\begin{abstract}
Both the Primary Care System and the Family Health Program are responsible for promoting and maintaining the health of the child population by providing full care and follow-up. For enabling the health teams to carry out their work it is fundamental to analyze the

Palavras-chave: Desnutrição Protéico-

calórica; Sistemas de Informação; Vigilância

em Saúde.

Key Words: Protein-calorie malnutrition;

Information Systems; Health Surveillance.

*Médica de Família e Comunidade e Hebiatria; mestranda em Saúde Pública, pela Universidade Federal do Ceará; preceptora e coordenadora regional da Residência em Medicina de Família e Comunidade da Secretaria Municipal de Saúde, Fortaleza, Ceará, Brasil.

**Médico de Família e Comunidade e Geriatria e Gerontologia; mestrando em Saúde Pública, pela Universidade Federal do ceará; preceptor e vicecoordenador geral da Residência em Medicina de Família e Comunidade da Secretaria Municipal de Saúde, Fortaleza, Ceará, Brasil.
\end{abstract}


bealth status of the population covered by the system. The Primary Care Information System (SLAB) is a priceless instrument for this purpose. The goal of this study is to demonstrate the sensitivity of protein-calorie malnutrition diagnosis performed by the Family Health Teams when only using the SLAB as data source and when performing active search of children from 0-23 months and 29 days of age, taking their anthropometric data. This cross-sectional study was carried out in the municipality of Patos de Minas (State of Minas Gerais), from January to April 2005. The prevalence of protein-calorie malnutrition informed by the SIAB found by teams $A$ and $B$ was of $2.35 \%$ and $2.5 \%$ respectively. The prevalence of malnutrition found by teams $A$ and $B$ through active search, collection of anthropometric data and weight/age ratio calculation were $14.12 \%$ and $13.75 \%$ respectively. This prevalence rate was higher than that described by the National Demographic and Health Survey, which was 5.7\%. The prevalence of protein-calorie malnutrition based on weight/ age ratio exclusively using the $S L A B$ as a data source results in an underdiagnosis of this health problem. Seen that the SIAB is a territorialized information system designed for allowing elaboration of population indicators in well defined areas of coverage, the authors propose a critical and constant evaluation of these data. The authors also suggest active search of all cases, involving the entire health team.

\section{Introdução}

Muitos conceitos têm sido utilizados para definir desnutrição. A desnutrição protéico-calórica, segundo a Organização Mundial de Saúde (OMS), é um conjunto de condições patológicas resultante da deficiência concomitante de calorias e de proteínas ${ }^{1}$.

As crianças e as gestantes são os grupos populacionais mais vulneráveis, nos quais as deficiências nutricionais costumam determinar maiores danos, pois, nessas faixas, aumentam de forma qualitativa e quantitativa as necessidades de nutrientes ${ }^{1,2}$.

Existe uma estreita relação entre desnutrição protéico-calórica e o grau de desenvolvimento socioeconômico de cada região. O Brasil, país de dimensões continentais, possui enorme diversidade social, econômica e cultural. Com isso, dentro de seu território há diversos processos sociais resultantes de diversificados "modos de viver" das populações. Vem ao longo de sua história enfrentando diversas crises econômicas com sérias repercussões sociais, sendo a desnutrição um problema de saúde e social relevante. Segundo Aerts e Giugliani, em última instância o estado nutricional é o retrato, no indivíduo e na população, da forma de estruturação do modelo de estruturação de uma dada sociedade ${ }^{2}$.

Habitualmente, desnutrição, pobreza e infecções, catalisadas pela iniqüidade e má distribuição da renda e de alimentos, participam de um ciclo vicioso em que um componente auxilia na perpetuação ou agravamento do outro $^{2}$.

A redução da mortalidade infantil e da mortalidade de crianças menores de cinco anos é ainda um grande desafio no país para os gestores, profissionais de saúde e a sociedade como um todo. Apesar da queda importante nos últimos anos, decorrente da redução da mortalidade pós-neonatal (28 dias a um ano de vida), os índices ainda são elevados. As causas perinatais, a pneumonia e a diarréia, associadas à desnutrição, são as principais nos primeiros anos de vida. Essa situação é agravada quando se reconhece que a maioria dessas mortes precoces pode ser considerada evitável ${ }^{3}$.

A promoção da saúde abrange um complexo de ações exercidas continuamente e integralmente com indivíduos, famílias e comunidades, a fim de propiciar melhor desenvolvimento físico, intelectual e emocional da população. É atribuição da Atenção Primária de Saúde e da ESF atuar na promoção e na manutenção do estado de saúde da população infantil por meio do atendimento e acompanhamento integrais ${ }^{4}$.

As equipes de saúde deverão incentivar ações de promoção à saúde e prevenção da desnutrição, como: orientação alimentar às famílias; acompanhamento pré-natal; incentivo ao aleitamento materno; orientação no desmame; acompanhamento do crescimento e desenvolvimento; uso de ferro profilático e de vitaminas para recém-nascidos prematuros (e de baixo peso) e lactentes a partir dos seis meses de vida; suplementação alimentar para gestantes 
desnutridas, nutrizes e crianças em risco nutricional. As equipes deverão estar preparadas para averiguar os índices antropométricos e avaliar o Cartão da Criança em todos os atendimentos, promover atividades educativas, identificar e captar gestantes e crianças desnutridas ou em risco nutricional ${ }^{3,4}$.

Estima-se que entre crianças de países em desenvolvimento 26,7\% (149,6 milhões) e 32,5\% (181,9 milhões) apresentem déficits de peso-idade e altura-idade, respectivamente ${ }^{5}$.

A Pesquisa Nacional sobre Demografia e Saúde, realizada em 1996, constatou que 10,5\% das crianças brasileiras de 0-59 meses sofrem de retardo no crescimento (baixa altura/idade), 5,7\% de baixo peso para idade e 2,3\% de baixo peso/altura. No meio rural a prevalência é maior que no meio urbano, respectivamente $4,6 \%$ e 9,2\%. O índice altura/idade possui maiores prevalências de crianças cuja altura é maior que dois desvios padrões abaixo da mediana na faixa etária $12-23$ meses $(15,1 \%)$, seguida da faixa entre 6 e 11 meses (10,2\%). O índice peso-idade possui os maiores déficits nas faixas etárias de 48 a 59 meses (6,8\%), 24 a 35 meses $(6,7 \%)$ e 12 a 23 meses $(6,3 \%)^{6}$.

Para a atuação das equipes de Saúde da Família é fundamental a análise de saúde das populações cobertas. Para esse fim o Sistema de Informação da Atenção Básica é instrumento de valor inestimável. Os principais instrumentos do SIAB são: o cadastramento, que permite a caracterização sociodemográfica das famílias cobertas; as fichas de acompanhamento de grupos, para priorização de grupos etários e de condições de risco; ficha de registro de procedimentos e notificações para acompanhamento das ações e serviços desenvolvidos pelas equipes de saúde da família. ${ }^{7}$

\section{Objetivos}

Demonstrar a sensibilidade no diagnóstico da desnutrição protéico-calórica realizado pelas equipes de Saúde da Família, quando são utilizados apenas dados primários como instrumentos de busca da adequação e posterior informação destes, via SIAB e por meio da busca ativa de crianças de 0-23 meses e 29 meses e obtenção de seus dados antropométricos.

Realizar análise crítica entre a prevalência de desnutrição encontrada no SIAB, busca ativa associada à antropometria e aos dados da literatura.

\section{Material e Método}

Trata-se de estudo seccional, realizado no município de Patos de Minas/MG, de janeiro a abril de 2005.

A população estudada foram crianças de 0 a 23 meses e 29 dias sob responsabilidade de duas equipes de Saúde da Família atuantes em zona urbana do município. A partir do trabalho dos agentes comunitários de saúde, conseguimos incluir no estudo 100\% das crianças cadastradas, sendo possíveis perdas por não-cadastramento.

As variáveis estudadas foram: a prevalência de desnutrição protéico-calórica com base no índice peso-idade em crianças menores que dois anos; a prevalência de desnutrição calculada pelo SIAB e dados antropométricos.

Foi feita uma busca ativa às crianças na faixa etária estudada, residentes na área de abrangência das equipes de Saúde da Família. Para isso utilizamos a Ficha A do SIAB e o Questionário de Risco e Vulnerabilidade Familiar (Anexo 1). Esses foram aplicados pelos ACs a partir da visita domiciliar mensal às famílias cadastradas.

Dividimos as crianças em grupos educativoterapêuticos, sendo os critérios para divisão: faixa etária, número de crianças/ faixa etária, viabilidade operacional dos grupos, facilidade de acesso da população-alvo ao local de realização dos grupos. Estes ocorreram com freqüência mensal, sendo cada criança e seus responsáveis convidados pelos ACS durante visita domiciliar. Foram realizadas buscas ativas aos faltosos.

Com relação às crianças analisadas, foram coletados dados de peso e altura. Foram analisados os índices peso/ idade, peso/altura e altura/idade para a monitoração do crescimento das crianças e diagnóstico da desnutrição e risco nutricional, conforme preconizado pela Organização Mundial de Saúde ${ }^{2,6,8}$. Utilizamos, para análise, o índice pesoidade, pois não era possível, por meio das informações 
anteriormente coletadas e demonstradas via SIAB, calcular os demais índices.

As prevalências de desnutrição em crianças de $0 \mathrm{a}$ 23 meses e 29 dias foram calculadas, e os dados obtidos foram comparados aos do SIAB e da literatura.

Os resultados do estudo foram divulgados para as equipes de Saúde da Família e para a população estudada. Foram seguidos os preceitos éticos para pesquisas em seres humanos nos termos do inciso II.2 da Resolução 196/96 do Conselho Nacional de Saúde.

\section{Resultados}

As prevalências de desnutrição protéico-calórica informadas no SIAB foram 2,35\% e 2,5\%, nas equipes A e $\mathrm{B}$, respectivamente.

As freqüências absolutas de crianças desnutridas nas equipes A e B comparadas com as freqüências encontradas no SIAB estão demonstradas nos gráficos 1 e 2 , respectivamente.

Gráfico 1. Freqüêmcia absoluta de desnutrição em crianças de 0 a 23 meses e 29 dias (índice peso-idade), Equipe A:

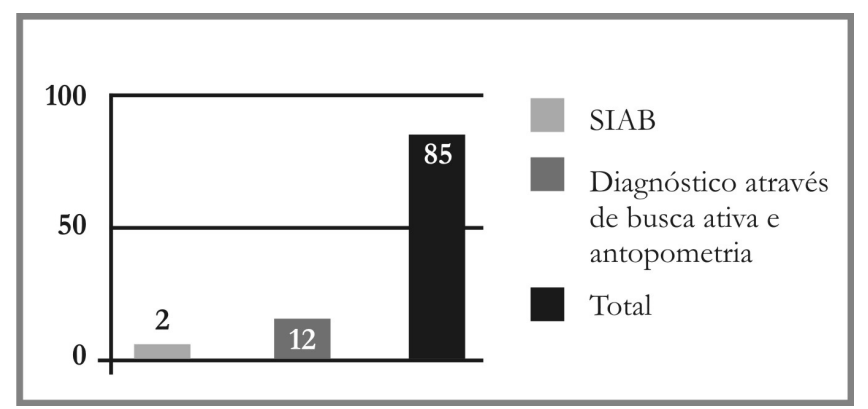

Gráfico 2. Freqüêmcia absoluta de desnutrição em crianças de 0 a 23 meses e 29 dias (índice peso-idade), Equipe B:

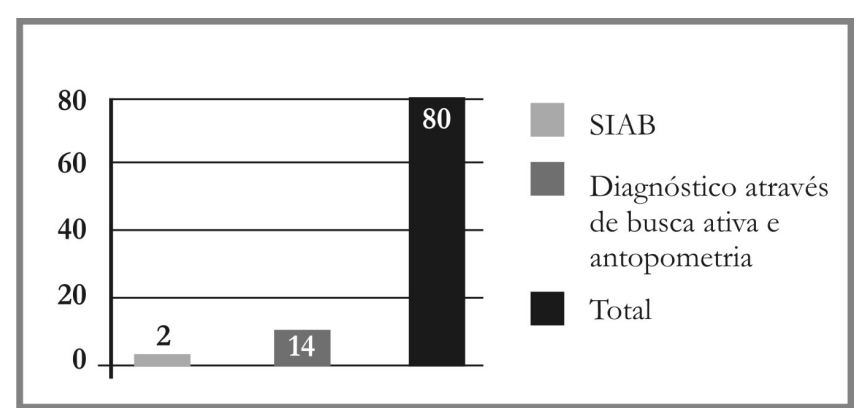

As prevalências de desnutrição encontradas a partir de busca ativa, dados antropométricos e cálculo dos índices peso-idade foram $14,12 \%$ e $13,75 \%$ nas equipes $\mathrm{A}$ e $\mathrm{B}$, respectivamente. Essas foram superiores à prevalência descrita pela Pesquisa Nacional de Demografia e Saúde, cuja prevalência foi $5,7 \%$.

\section{Discussão}

As prevalências de desnutrição protéico-calórica com base no índice peso-idade, mediante exclusivamente a utilização do SIAB como fonte de dados, levam ao subdiagnóstico do problema.

A desnutrição protéico-calórica e o risco nutricional vêm sendo freqüentemente subdiagnosticados pelas equipes de Saúde da Família. A baixa sensibilidade dos métodos aplicados para identificar as crianças desnutridas e conseqüentes subdiagnóstico, subnotificação e informação de dados irreais levam os profissionais de saúde a subestimarem o problema e, com isso, não planejarem adequadamente as ações preventivas, educativas e curativas a serem realizadas pelas equipes de Saúde da Família.

Concluímos que a falha no diagnóstico da desnutrição protéico-calórica ocorre devido à coleta de dados. Os dados colhidos pelos Agentes Comunitários de Saúde são vulneráveis ao viés de informações, pois dependem das informações fornecidas pelos pais ou responsáveis, os quais, por desconhecimento do problema e/ou nãoaceitação deste, podem fornecer informações falsonegativas. Outro ponto a ser refletido é a exclusão das crianças entre 24 e 59 meses dos dados a serem utilizados pelas equipes de Saúde da Família, uma vez que a prevalência do agravo, segundo a literatura, é maior nessa faixa etária (PNDS, 1997).

Por meio da análise dos resultados deste trabalho, concluímos que a busca ativa de crianças desnutridas pertencentes à área de abrangência - o território - de uma equipe de Saúde da Família e a obtenção dos seus dados antropométricos possuem maior sensibilidade e evitam o subdiagnóstico do problema.

Propomos o maior empenho de toda a equipe de 
Saúde da Família para o diagnóstico e o tratamento das crianças desnutridas, por meio de uma abordagem multiprofissional.

A capacitação adequada dos profissionais de saúde para abordagem do problema é indispensável para coleta adequada de dados e cálculo de indicadores, utilizando corretamente o Cartão da Criança.

A análise crítica dos dados apresentados deve ser feita pelos profissionais, pois o conhecimento da realidade epidemiológica do território de atuação da equipe é fundamental para planejamento e execução de ações em saúde.

Tratando-se o SIAB de um sistema de informação "territorializado", cujos dados possibilitam a construção de indicadores populacionais referentes a áreas de abrangência bem-delimitadas, propomos a avaliação crítica e constante desses dados.

\section{Referências}

1.Goulart LMHF; Amaral TM. Desnutrição energéticoprotéica. In: Alves CRL; Viana MRA. Saúde da Família: Cuidando de crianças e adolescentes. Belo Horizonte (MG): COOPMED; 2003. p.135-143.

2.Aerts DRGC; Giugliani ERJ. Desnutrição. In: Duncan BB; Schmidt MI; Giugliani ERJ. Medicina ambulatorial: Condutas de atenção primária baseadas em evidências. 3. ed. Porto Alegre (RS): Artmed; 2006. p.269-275.

3.Brasil. Ministério da Saúde. Secretaria de Atenção à Saúde. Departamento de Ações Programáticas Estratégicas. Agenda de compromissos para a saúde integral da criança e redução da mortalidade infantil. Brasília (DF): Ministério da Saúde; 2005.

4.Organização Panamericana de Saúde. Atenção integrada às doenças prevalentes na infância (AIDPI): manual para capacitação de profissionais da atenção primária. Fortaleza (CE): Escola de Saúde Pública do Ceará; 2005.

5.World Health Organization. Nutrition form health and development. Geneva: WHO/NHD; 2002.

6.Sociedade Civil Bem-Estar Familiar no Brasil. Pesquisa nacional sobre Demografia e Saúde. Rio de Janeiro: BEMFAM; 1997.
7. Brasil. Ministério da Saúde. SAA/DAB Sistema de Informação da Atenção Básica. Disponível em: http:// dtr2004.saude.gov.br/dab/caadab/documentos/ siab2001.pdf

8.World Health Organization. Working group: use and interpretation of anthropometric indicators of nutricional status. Geneva: WHO; 1995.

\section{Endereço para correspondência:}

Tatiana Monteiro Fiúza

Avenida dos Coqueiros, s/n

Condomínio Summer Ville, Casa $n^{\circ} 133$

Praia do Cumbuco

Caucaia (CE)

Cep: 61600-970

\section{Endereço eletrônico:}

tatitatimfc@gmail.com 
Anexo 1. Questionário de Risco e Vulnerabilidade Familiar.

Responsáveis pela aplicação do questionário: médico, enfermeira, odontólogo, THD, assistente social AE ou ACS.

Endereço:

PSF:

MA:

FA:

1-Crianças com pouca idade - Menor de um ano de vida? （）SIM （）NÃO

2-Episódios anteriores de diarréia em crianças? ( ) SIM ( ) NÃO

3-Analfabetismo dos pais ou ausência do pai? （）SIM ( )NÃO

4-Baixa renda per capita (renda menor que 60 reais por membro da família)? （）SIM （ )NÃO

5-Presença de três ou mais crianças em casa? （ ) SIM （）NÃO

6-Mãe com menos de 18 anos? （） SIM （）NÃO

7-Falta de água encanada e saneamento básico (associada a uma redução de 20-30\% na morbimortalidade)?

( ) SIM ( ) NÃO

8- Presença de lixo na rua ou em terrenos próximos? （ ) SIM （） NÃO

8-Falta de hábitos saudáveis de higiene doméstica e pessoal (principalmente lavagem das mãos)? （）SIM （）NÃO

9-Difícil acesso aos serviços de saúde? ( ) SIM ( ) NÃO

10-Desmame precoce (crianças desmamadas apresentam risco 14,2 vezes maior de morrer por diarréia)?

2 pontos ( ) SIM ( ) NÃO

11-Estado nutricional deficiente (incidência maior, episódios mais graves e com maior letalidade em crianças desnutridas)?

2 pontos ( ) SIM ( ) NÃO

12-Prematuridade ou baixo peso ao nascer/Gemelaridade? （）SIM （）NÃO

13-História de hospitalização por diarréia e/ou PNM?- 2 pontos （）SIM （）NÃO

14-Fatores socioculturais a seguir (cada resposta afirmativa $=1$ pontos): Desemprego; Relação Conjugal

Instável e Desequilibrada; Falta de Planejamento Familiar; Isolamento social.

Número de pontos $=$

15-História pregressa de violência familiar e/ou prostituição? - 3 pontos （）SIM （）NÃO

16-Abuso de álcool e/ou drogas ilícitas? - 3 pontos （）SIM （）NÃO

17-Relação morador/cômodo:

Se maior que $1=3$ pontos

Se igual a $1=2$ pontos

Se menor que $1=0$ ponto

18-Pacientes sintomáticos respiratórios e/ou TBC no domicílio? 3 pontos （ ) SIM （ ) NÃO

20- Manchas com alteração de sensibilidade ou pacientes com hanseníase no domicílio? - 3 pontos - （） SIM （）NÃO

21- Pacientes hipertensos/Diabéticos? （）SIM （）NÃO

22- Gestantes? ( ) SIM ( ) NÃO

23- Pacientes com DST e/ou AIDS? （ ) SIM （ ) NÃO

24- Pacientes acamados? - 3 pontos - （）SIM （）NÃO

25- Pacientes portadores de outras doenças crônicas? ( ) SIM ( ) NÃO

26- Família reside em casa de taipa ou papelão? （ ) SIM （ ) NÃO

27- Presença de animais domésticos no interior do domicílio? （）SIM （）NÃO

ESCORE DE RISCO:

1 RISCO 1: 0-3 pontos (BAIXO RISCO)

2 RISCO 2: 4-8 pontos (RISCO MODERADO)

3 RISCO 3: 9-12 pontos (ALTO RISCO)

4 RISCO 4: > ou = 12 pontos (RISCO MUITO ALTO - "URGÊNCIA")

Observações relevantes:

Integrante da equipe responsável pela visita:

Data: 